\title{
presa kariba
}

Información facilitada por la Federal Power Board de Rodesia y Niasa

$531 \cdot 38$

\section{S I N O P S I S}

La Federación de los países de Rodesia y Niasa ha emprendido Ja construcción de la presa bóveda Kariba, que utilizará las aguas del caudaloso río sudafricano Zambeza

antes de entrar en el vecino territorio de Mozambique.

La altura máxima de la presa será de $128 \mathrm{~m}$, la potencia hidroeléctrica prevista es de $100.000 \mathrm{kw}$. dos centrales subterráneas y un embalse de $160.000 \mathrm{Hm}^{3}$.

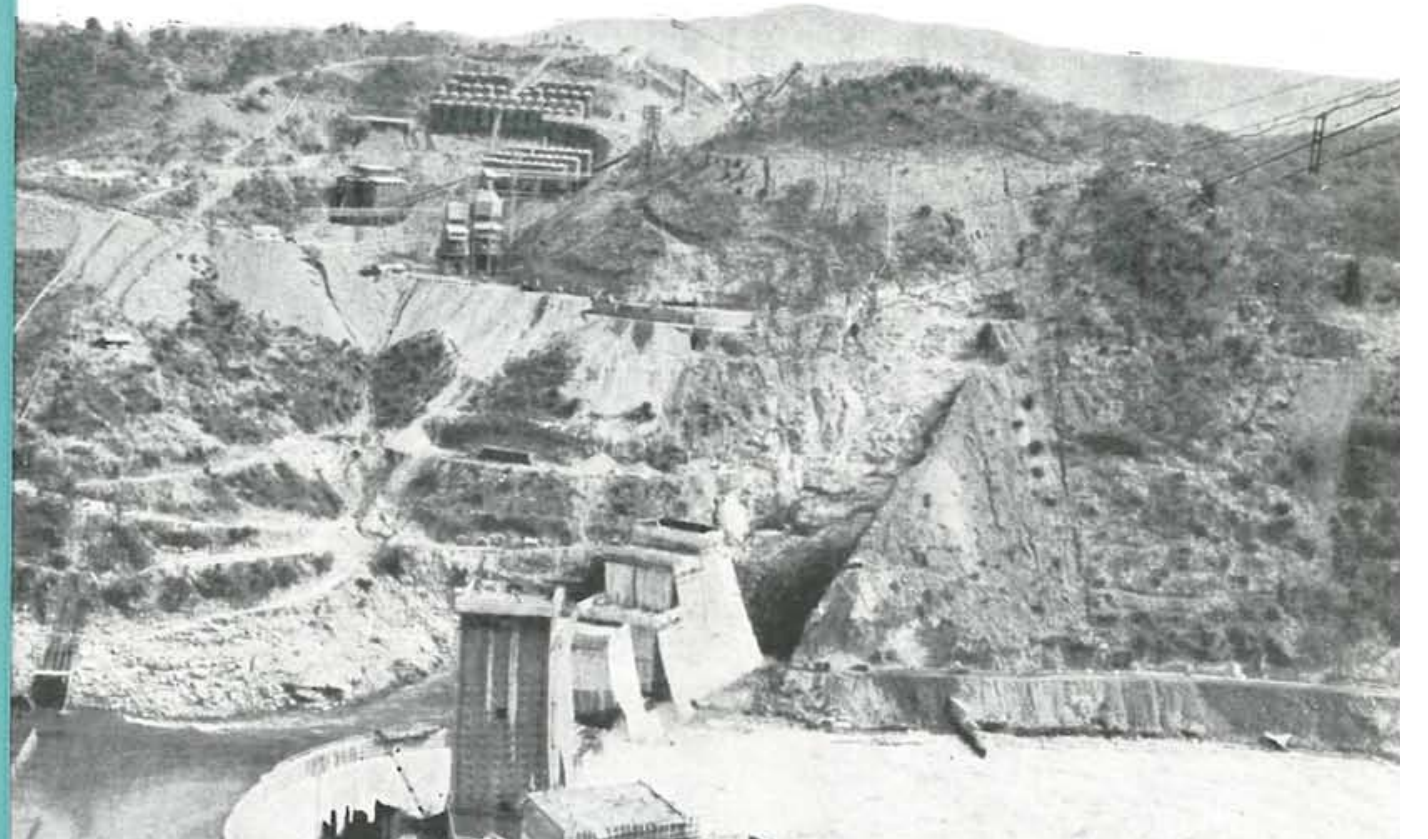

El aprovechamiento hidroeléctrico del río Zambeza, dentro del tramo correspondiente a los territorios que el mismo cruza, y que se han agrupado para constituir la Federación de los países africanos de Rodesia y Niasa, constituye una ambiciosa opción para la ejecución.

de uno de los saltos más potentes en el actual campo y desarrollo mundial hidroeléctrico. 
Pero si por si solo no fuera esto de gran mportancia realizadora, basta mirar u poco retrospectivamente para apercibirse de la capacidad actual civilizadora para emprender trabajos de enorme volumen donde por su situación geográfica $\mathrm{y}$ condiciones climáticas parecia poco menos que impracticable hace tan solo unas décadas de años. Plausible mérito el de estos nobles y jóvenes paises en su indómito esfuerzo para lograr el aprovechamiento de sus riquezas sar creciente civilización y bienestar general.

EI esfuerzo no tiene límites, pues no se trata única y exclusivamente de construi y proyectar en el papel, sino que hay que de los centros de producción y donde no existian las vias necesarias de trane para abastecer una obra tan importante. pa reunión y cumulación tan créditos cursos economicos ha presentado no inconvenientes y responsables decisiones, pues hay que hacer frente a unos 80 milo nes de libras de gastos, es decir, de 10.000 millones de pesetas al cambio actual, aproximadamente.

El aprovechamiento inmediato que se desprende de esta importante obra es el hidroeléctrico, al que se aparejan otros secundarios, de pesca, turismo y de más notable interés. La potencia que ha de instalarse es del orden de unos $100.000 \mathrm{kw}$, para cuyo transporte han de construirse las líneas, estaciones y subestaciones necesarias para llevar la energia a lugares de consumo, alejados de la presa Kariba.

Dada la gran extensión y altura del remanso y nuevo nivel de aguas, respectivamente, aparecen grandes zonas que seran anegadas; y como una gran parte de ella e hallan habitadas por indigenas, que se han agrupado formando poblados, ha sido necesario prever su traslado y reconstrucción de estos centros rústicos a otros lugares no inundables y más urbanizados. Esto ha constituído un nuevo aspecto del problema, por tratarse de unos 50.000 habitantes afectados con el nuevo cambio de nive de aguas. Esta transmutación será un poco laboriosa, pues el personal indigena es in crédulo a la posibilidad de un aumento no

\section{Prospección de parajes}

Como de la zona donde se halla situada actualmente la presa sólo existían mapas a gran escala, en 1949 se procedió a un levanamiento topográfico general, a escala $/ 5.000$, para poder estudiar sobre un plano cotado las posibles soluciones de emplaza miento de la presa.

\section{Hidrología local}

De los aforos y conocimientos existentes recogidos por el Departamento de Irrigación del Estado Federal, y con ayuda de los recientes levantamientos topográficos, se pudo llegar a una delimitación del embalse pro yectado, cuy longitud de remanso es de unos 280 kilometros.

\section{Geología}

El tramo del río donde se halla situada la presa está constituido por un valle angosto, de gran longitud, que forma una cerrada natural muy apropiada para levantar el dique de cierre. Una primera eliminación redujo el campo de posibilidades a esta zona, sometido después a serios estudios geológicos y sondeos de reconocimiento para llegar
nalmente al lugar optimo de ubicación.

La memoria geológica asignaba un terreno de gneis biotitico, compacto, impermeable y un banco subyacente de inmejorables condiciones. Aunque el terreno no es uniorme y es atravesado por zonas de distinta calidad, no ha presentado dificultades en su excavacion y cimientos. Teniendo a la vista estos datos, calicatas, galerias de registro y sondeos, asi como un conocimiento proximo de la superficie de las márgenes del rio, el lugar de ubicación se eligió a tural.
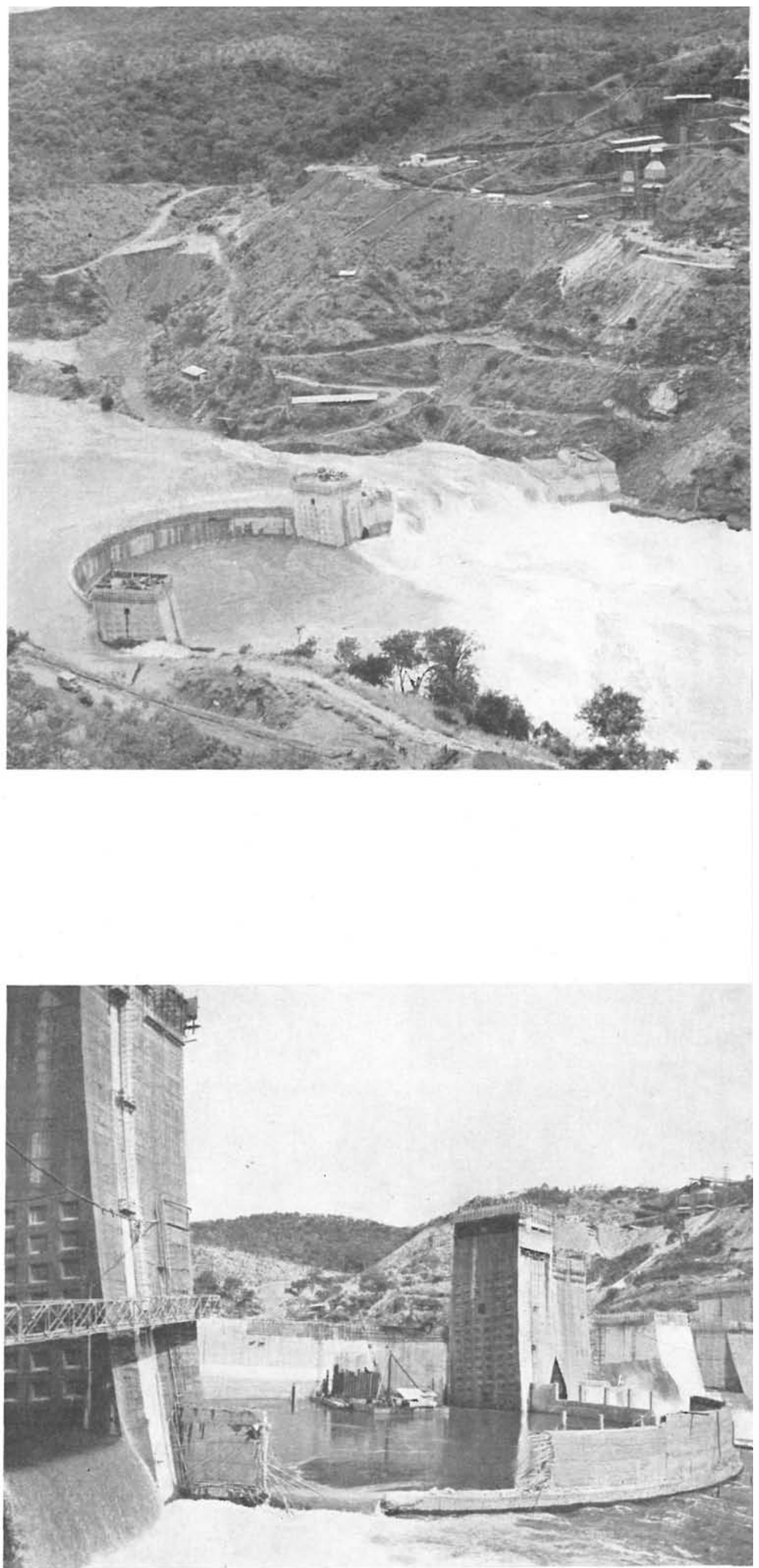
Debido a la estrechez del valle en esta parte del rio, no se disponia de grandes superficies llanas para las instalaciones auxiliares.

\section{El proyecto}

Como consecuencia de los estudios preliminares se redactó, a principios del año 1956, el proyecto de construcción de la presa, centrales, túneles y otras instalaciones permanentes. En la formación del proyecto han colaborado notables especialistas europeos dedicados a esta especialidad, y se consultaron también grupos de Casas para el suministro del equipo electro-mecánico.

Con objeto de comprobar los resultados analiticos, se procedió al estudio del aprovechamlento en modelo a escala reducida.

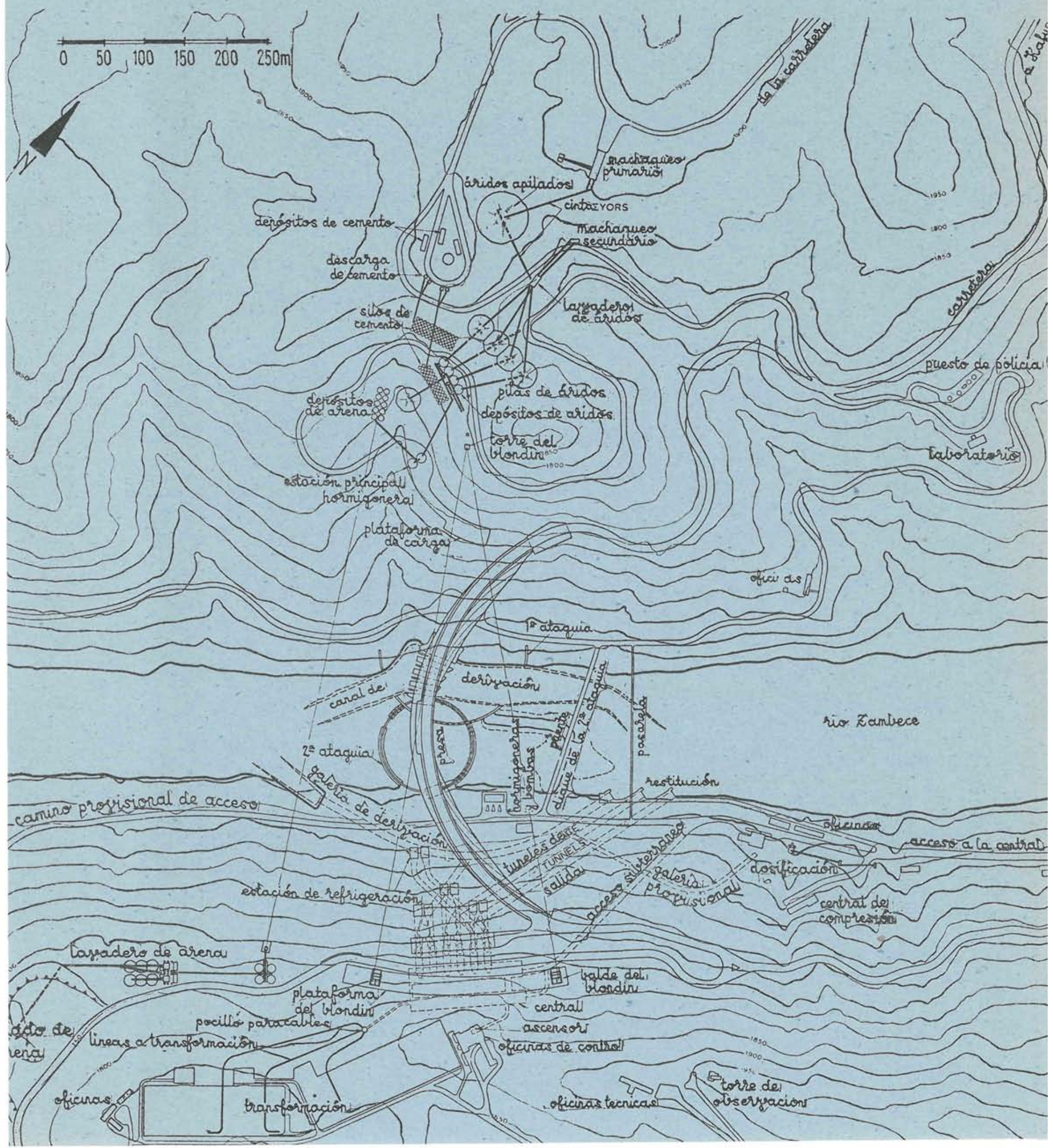




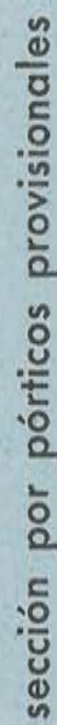
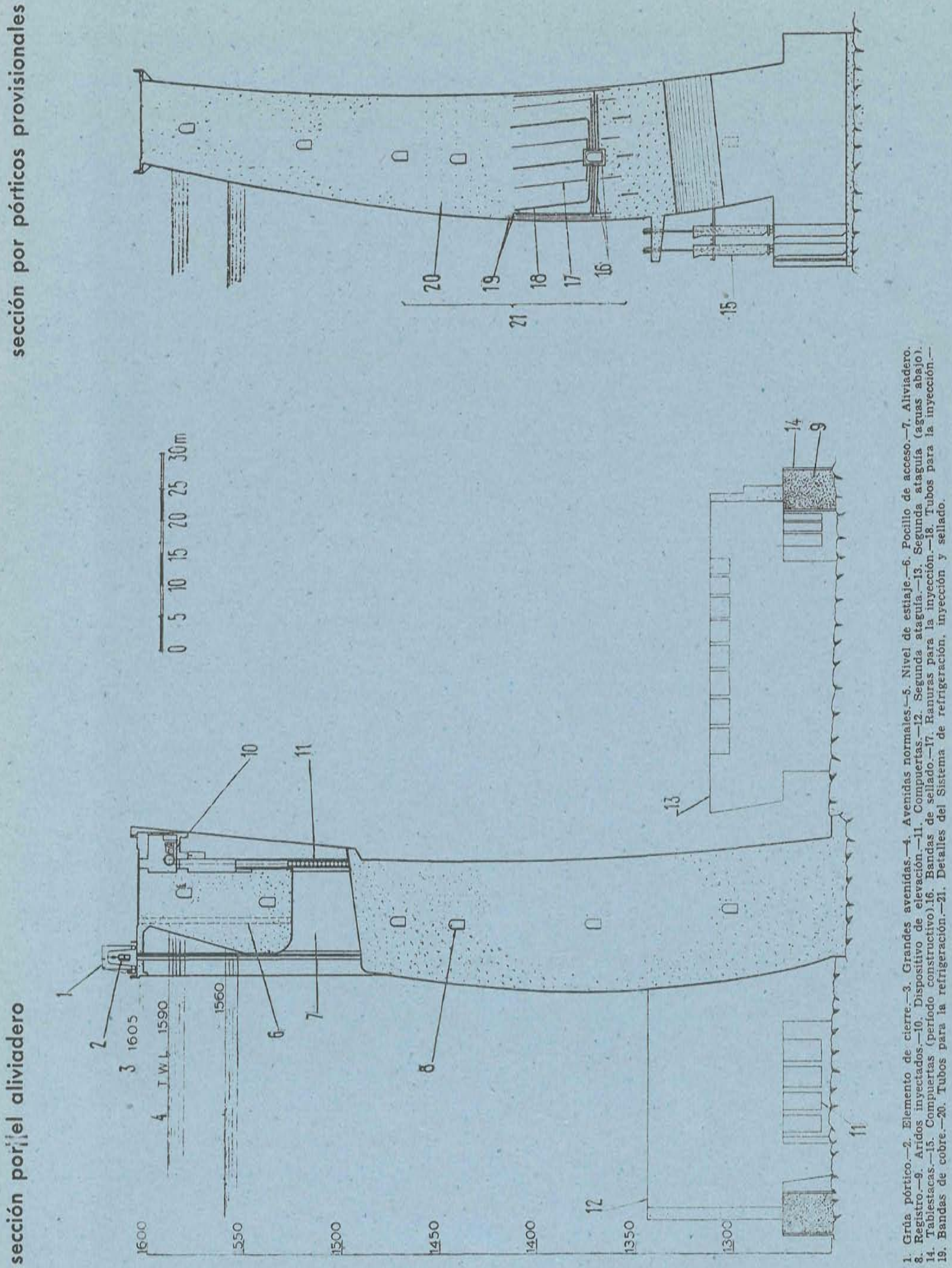


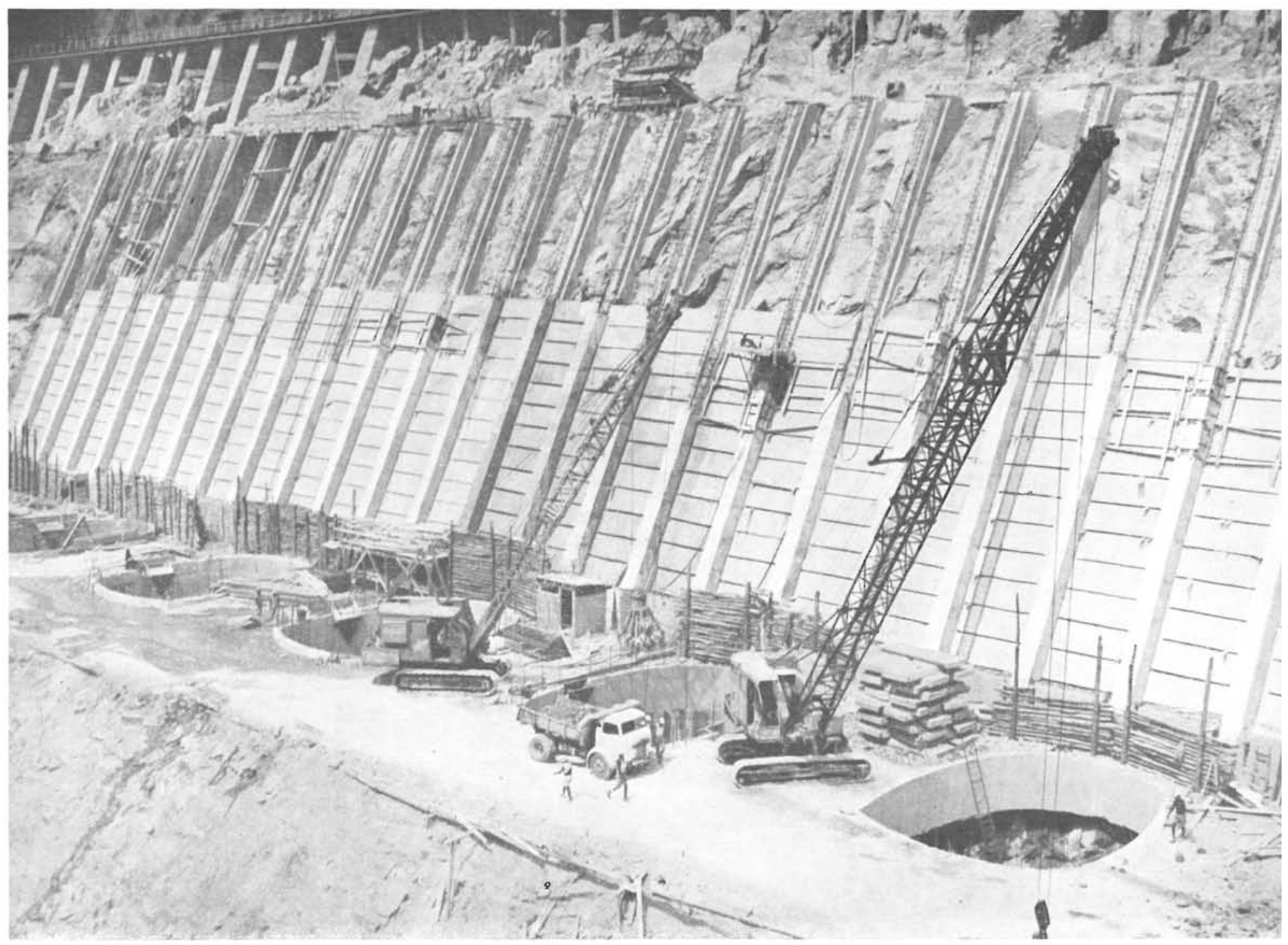

\section{Instalaciones preliminares}

Para ganar tiempo, $y$ antes de terminarse el proyecto, se procedió a la construcción de la gran carretera y accesos, acantonamientos para el personal, reconocimientos, puente y pasarela de servicio sobre de la ataguía de la margen norte del río.

En estos y sucesivos trabajos se ha requerido de personal especializado que los contratistas se han encargado de reclutar en sus propios países. Los trabajos que no requieren una especialización depurada se confían a la mano de obra local $y$, entre este personal, ración y aprendizaje.

\section{La presa}

La presa, tipo bóveda, se halla situada a unos cuatro kilómetros aguas abajo de la entrada del río en un cauce cerrado. De haber construido la presa al final de este valle cerrado se hubiesen podido ganar unos metros más de altura en el salto hidrostático formado, pero el terreno en esta parte no se prestaba muy bien para el apoyo
de cimientos y presentaba ciertas dificultades la derivación de aguas.

La presa se halla, por carretera, a unos $380 \mathrm{~km}$ de Salisbury; a unos 190 de Lusaka, y, siguiendo el curso del río hacia aguas arriba, a unos $480 \mathrm{~km}$ de las cataratas llamadas "Victoria Falls".

La estructura es de hormigón, de $128 \mathrm{~m}$ de altura respecto a cimientos y de, aproximadamente, $580 \mathrm{~m}$ de longitud. Una vez lleno el embalse, el nivel de aguas se elevará a $103 \mathrm{~m}$ sobre el correspondiente a aguas en estiaje.

El aliviadero de vertedero se ha situado en la zona central de la obra, y estará constituído por cuatro tramos de $9,45 \times 9,15 \mathrm{~m}$ de sec- ción cada uno. La lámina vertiente, cuando el embalse descargue, caerá en un cuenco de amortiguamiento con solera de hormigón, que será visitable cuando los azudes no viertan y, por tanto, permitíń reconocer el estado de los efectos erosivos si los hay.

Todo se ha previsto de tal forma que, en régimen normal, y con todas las turbinas instaladas, el embalse almacenará las grandes avenidas, constituyendo una reserva y dejando verter al aliviadero un volumen de menor consideración.

\section{Las centrales}

El aprovechamiento tendrá dos centrales subterráneas, una en cada margen del río, y la primera de éstas se construirá en la margen derecha y tendrá $140 \mathrm{~m}$ de longitud total. Esta central se equipará de seis grupos con tomas independientes, Dos de estas tomas se situaran en la parte inferior de la presa con objeto de producir energía con aguas bajas, $y$, cuando el nivel del agua embalsada las de nivel superior. Esta forma de operar permitirá generar desde que el embalse lo permita. La otra central, situada en la margen izquierda, tendrá el mismo o mayor equipo electro-eléctrico en lo que a potencia se refiere.

Las turbinas son del tipo Francés, de eje vertical, y utilizarán un salto de unos $92 \mathrm{~m}$. Debido al gran volumen y peso de los generadores, éstos se han subdividido en tres partes para facilitar su transporte y montaje. Las aguas turbinadas serán restituídas por medio de tres túneles, uno de los cuales será el utilizado para la derivación de aguas durante el período constructivo. La regulación de la alimentación se realizará por medio de cámaras de expansión.

El acceso a las centrales se efectuará por medio de rampas en túnel, habiéndose previsto los correspondientes pocillos para cables $\mathrm{y}$ ventosas para la ventilación. El cuadro de mando $\mathrm{y}$ oficinas se hallará a unos $198 \mathrm{~m}$ de altura sobre la planta de la central. 

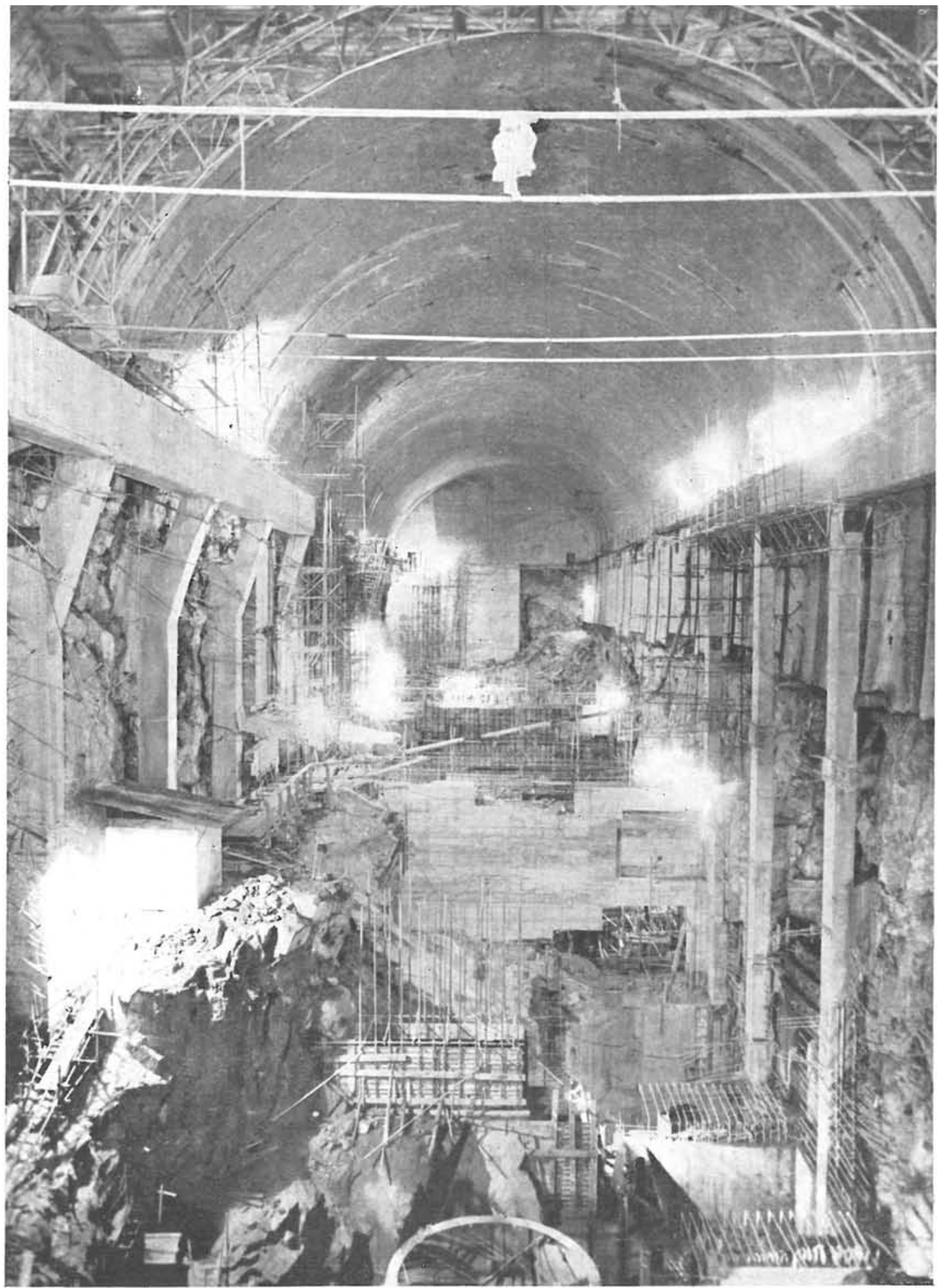

En el acceso entre la sala de máquinas y planta de cuadros se construirán dos ascensores o montacargas: uno de ellos, rápido, con capacidad para seis personas, y el otro, que también podrá utilizarse para el transporte de material ligero, con capacidad para 12 personas.

El voltaje de los alternadores será elevado por una transformación monofásica. Estos transformadores se exterior, y desde aquí se transportará a las subestaciones de la red a $330 \mathrm{KV}$ de tensión.

\section{Construcción}

La construcción de la presa se ha subdividido en cuatro fases o periodos constructivos. En el primero, que se extiende de 1955 a 1956, ha consistido en la construcción de una ataguía circular, de pared delgada, que protegerá la construcción de una parte de la presa en su interior. Posteriormente, se construyó un canal de derivación en el interior de esta ataguia, que serviria para derivar las aguas en un momento dado. Concomitantemente a la construccion de esta atagula se construyo un tunel de derivación en la margen opuesta. Este tunel el canal central del lecho natural. Los caudales previstos para el río son de $450 \mathrm{~m}^{3} / \mathrm{s}$ durante el estiaje, $5.660 \mathrm{~m} \mathrm{~m}^{3} / \mathrm{s}$ en el período húmedo y $10.750 \mathrm{~m}^{3} / \mathrm{s}$ en un corto tiempo durante el año.

Durante esta fase se inició la construcción de los soportes del puente que debía salvar el río y unir las dos márgenes. También se prepararon los trabajos para la pasarela colgante de servicio.

La segunda fase de la ejecución, que comprendió el período de aguas altas, en 1956-57, consistió en construir las dos partes laterales de la presa, es decir, los estribos. La parte de la margen izquierda, protegida por la ataguía, se construyó hasta lograr una altura de presa que emergía sobre el nivel de aguas, mientras que la parte de la margen opuesta se construyó en seco y hasta el límite del perímetro mojado. 
La parte construída en la margen izquierda, dentro de la ataguía, tiene cuatro huecos, de $7,60 \mathrm{~m}$ de luz y $26.8 \mathrm{~m}$ de altura que sirvieron para derivar parcialmente las aguas durante la construcción de la parte más profunda del río que corresponde al canal o parte central.

En la tercera fase, de aguas bajas, ejecutada en el año 1957, se realizaron los trabajos que han constituído el período crítico de la construcción, ya que en este período de tiempo se debía cerrar el caudaloso río y permitir levantar la presa al mayor nivel posible emergente de las aguas.

Al empezar a descender el nivel de aguas del río, se procedió a abrir paso a través de la ataguía de la margen izquierda para ir derivándolas parcialmente, pues el túnel de derivación estaba ya en servicio. En el
interior de la ataguia se había preparado un canal que las encauzaba hacia los cuatro huecos dejados a tal efecto al construir esta parte lateral de la presa.

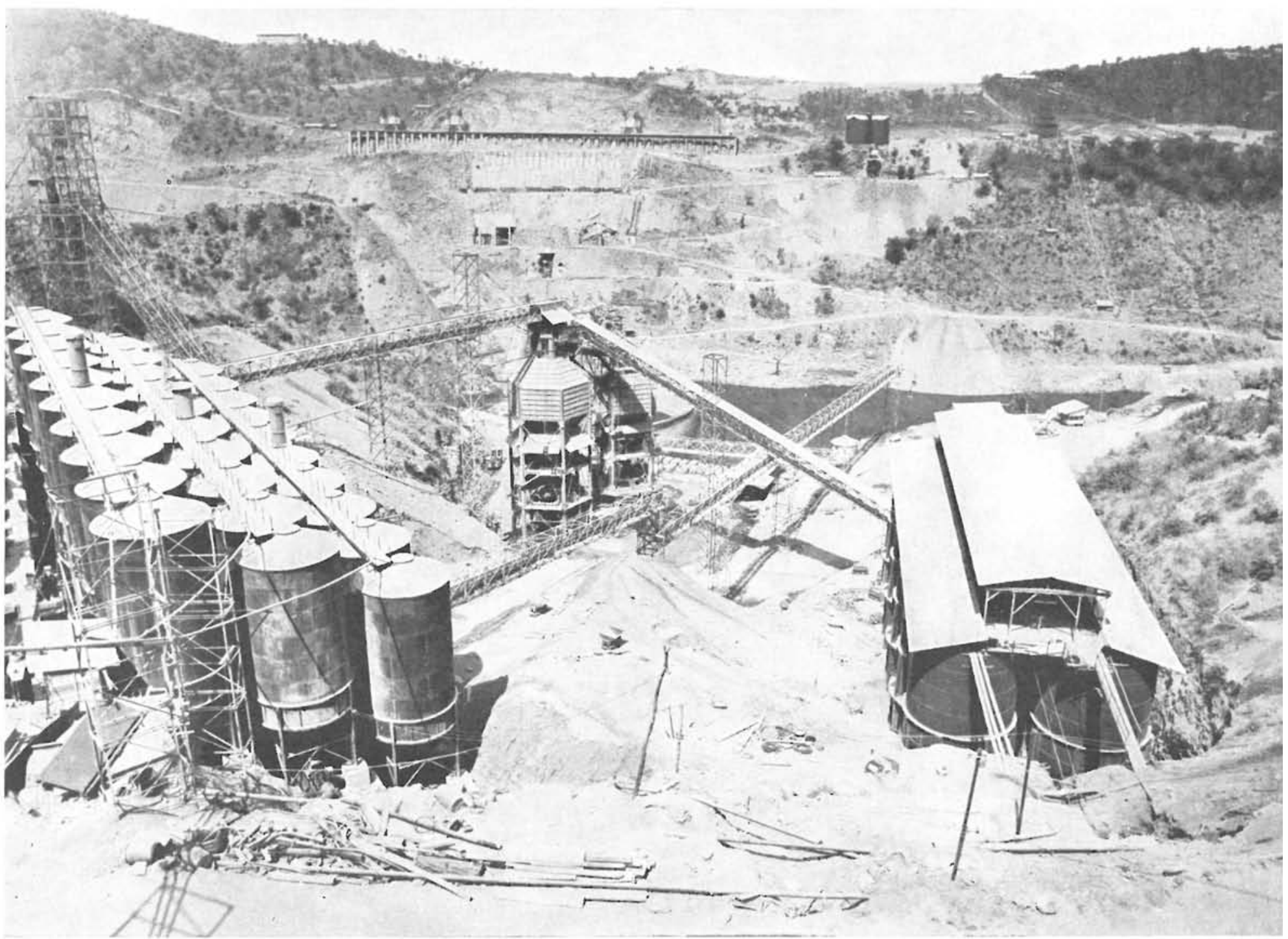

Inmediatamente aguas abajo del canal central del río, comprendido entre los dos trozos de presa previamente construídos, se empezó a depositar relleno para formar el dique de aguas abajo de la ataguía central. Como las aguas estaban tranquilas en esta zona, esta operación no presentó dificultad. Sobre este relleno se hincaron dos filas de tablestacas, las cuales se impermeabilizaron después inyectando mortero entre ellas E1 muro de aguas arriba de cierre de esta ataguía, circular, de pared delgada, asi como el de aguas abajo, se apoyaban contra los dos trozos de presa previamente construidos, permitiendo así trabajar en seco dentro de la ataguia para levantar la obra de cimientos y lograr la mayor altura posible en esta fase, que ya debía dejar la presa a falta de cierr
ir constituyendo el embalse.

Durante la cuarta y última fase constructiva, correspondiente a 1958, la construcción se llevará activamente a cabo utilizando los blondines para la colocación del hormigón.

En el estiaje de este período se cerrará el túnel de derivación y los huecos dejados para desagủe en la parte de presa de la margen izquierda, y el embalse empezará a almacenar.

En marzo de 1958 sobrevino una enorme avenida, con caudales máximos excepcionales del orden de 16.000 metros cúbicos/segundo, que irrumpieron en las ataguías causando algunos destrozos, los cuales, sin ser de metros cúbicos/segundo, que irrumpieron en las ataguias causando algunos destrozos, los cuales, sin ser de ser recuperada en el curso de los trabajos que todavía faltan para su total terminación.

Sólo para la construcción de la presa se habrán de colocar en obra unos $900.000 \mathrm{~m}^{3}$ de hormigón; y si a éstos añadimos unos 100.000 para centrales y anexos, se comprenderá la gran importancia que ha de concederse a la ejecución de este aprovechamiento situado en una zona tan alejada del mar y centros industriales. 